\title{
LESIÓN CENTRAL DE CÉLULAS GIGANTES EN MANDÍBULA, REPORTE DE CASO
}

\section{MANDIBULAR GIANT CELL LESION, CASE REPORT}

\author{
Aguilar-José David ${ }^{1}$,Vallejo-Rodrigo Fernando ${ }^{2}$,Gárate-Juan Carlos ${ }^{3}$,Terreros-Peralta Andrea Catalina ${ }^{4}$ \\ 1 *Cirujano y Patólogo Bucal, Docente de la Universidad Católica de Cuenca, Sede Azogues. Ecuador \\ ${ }^{2}$ MSc en Estomatología, Docente de la Universidad Católica de Cuenca, Sede Azogues. Ecuador \\ ${ }^{3}$ Estudiante de Odontología. Azogues. Ecuador \\ ${ }^{4}$ MSc en Gerencia en Salud, Especialista en Odontopediatría. Azogues. Ecuador \\ *daguilarm@ucacue.edu.ec
}

\begin{abstract}
Resumen
La lesión central de células gigantes multinucleadas (LCCGM), también llamada granuloma central de células gigantes, es de una neoplasia benigna, de evolución lenta y de carácter no odontogénico, que puede presentarse en los huesos maxilares, especialmente la mandibula y se caracteriza por ser asintomático y comúnmente es un hallazgo radiográfico. Este artículo presenta el caso de una paciente de 18 años sin antecedentes médicos de relevancia a quien se le encuentra un defecto radiolúcido a nivel del primer molar inferior izquierdo, el cual se extirpa mediante cirugía bajo anestesia local y se envía a análisis histopatológico resultando compatible con lesión central de células gigantes. El objetivo de este artículo es presentar esta lesión central de células gigantes multinucleadas en mandíbula para ampliar los conocimientos clínicos, radiográficos e histopatológicos para colaborar con nuestros estudiantes y colegas odontólogos, en el buen direccionamiento de lesiones intraóseas de carácter no odontogénico.
\end{abstract}

Palabras clave: lesión central de células gigantes, células gigantes multinucleadas, granuloma de células gigantes, tumor no odontogénico.

\begin{abstract}
Central multinucleated giant cell lesion (LCCGM), also called central giant cell granuloma, is a benign non-odontogenic neoplasm that can occur in the maxillary bones, especially the jaw, and is characterized to be asymptomatic and is usually an exclusive radiographic finding. This article presents the case of an 18-year-old patient with no relevant medical history who is found to have a radiolucent defect apically of the lower left first molar, which is removed by surgery under local anesthesia and the sample submitted to histopathological analysis, which is compatible with central multinucleated giant cell lesion. The objective of this article is to present this multinucleated giant cell lesion in Jaws to expand the clinical, radiographic and histopathological knowledge to collaborate with the good diagnostic routing of nonodontogenic intraosseous lesions to our students and dental colleagues.
\end{abstract}

Key words: central giant cell lesion, multinucleated giant cells, giant cell granuloma, no odontogenic tumor.

\section{INTRODUCCIÓN}

La lesión central de células gigantes multinucleadas (LCCGM), también llamada granuloma central de células gigantes, se trata de una neoplasia benigna, de evolución lenta y de carácter no odontogénico, que puede presentarse en los huesos maxilares; descrita inicialmente por Jaffe en el año de 1953 el mismo que concluyó que se trataba de un proceso de reparación a una injuria, motivo por el cual la denominó, granuloma reparativo de células gigantes. ${ }^{1,2}$ Actualmente la Organización Mundial de la Salud (OMS) describe la lesión de células gigantes (LCCG) como una lesión benigna no odontogénica, conformada por un estroma fibroso con múltiples zonas hemorrágicas y la presencia de células gigantes multinucleadas dispersas. En ocasiones se pueden observar trabéculas de tejido óseo residual. ${ }^{3,4}$

Con respecto a su epidemiologia se reporta que puede aparecer a cualquier edad, pero la mayor cantidad de casos se dan entre los 10 a los 30 años de edad y la aparición de la LCCG se da en una relación mujeres hombres de 2 a $1 .{ }^{2,5,6}$ En el año 2007 Lange y col. reportaron en su estudio, que la mayor prevalencia en mujeres oscilaban en edades de 15 y 19 años, mientras que en hombres se presentaba en edades comprendidas entre 10 y 14 años, considerando este grupo como picos de incidencia de la LCCG. ${ }^{6}$ Dentro 
de la afectación del sistema estomatognático se describe una mayor incidencia en el maxilar inferior $(70 \%)$; con respecto al maxilar superior y dentro de este, es más común en la zona premolar y molar, aunque también se han descrito casos en la zona del cóndilo mandibular ${ }^{3,7,8}$

Dentro de las características clínicas de la lesión destaca un abultamiento o tumefacción de progreso lento y asintomático, que en los casos de detección precoz se manifiesta en su mayoría como un hallazgo fortuito ya sea en el examen físico o en el examen radiográfico. ${ }^{1,6}$ Sin embargo, en lesiones de mayor volumen puede encontrarse cambio de la coloración de la mucosa a un color azulado parduzco y puede estar relacionado con desplazamiento dental contiguo. ${ }^{1,9}$ Igualmente en lesiones avanzadas, especialmente en el maxilar superior, se observará asimetría facial evidente, además de sangrado nasal espontaneo y obstrucción nasal, según sea la invasión al espacio del seno maxilar. ${ }^{2}$

Radiográficamente la LCCG se presenta como una imagen radiolúcida a levemente mixta, de bordes definidos unilocular o multilocular, que puede estar acompañada de desplazamiento dental contiguo, rizólisis y perforación de las corticales óseas maxilares. $^{7-9}$

La terapéutica clásica para la LCCG es la exéresis de la lesión, debido a su consistencia que permite mediante curetaje simple retirar la totalidad de la lesión en la mayor parte de los casos. Además se reporta para lesiones de carácter más agresivo tratamientos que van desde el curetaje con criocirugía del lecho de la lesión, resección quirúrgica con osteotomía periférica hasta la resección en bloque acompañada de la reconstrucción del defecto óseo. ${ }^{1,2,8,9}$ Actualmente se han reportado diversos tipos de tratamientos coadyuvantes y conservadores como son el uso de corticoides intralesionales, el tratamiento con calcitonina, interferón alfa, y también con anticuerpos monoclonales humanos como es el RANK-L y proteínas inhibidoras de la tirosinasa como el IMATINIB. ${ }^{9}, 10$

El objetivo de este caso clínico es presentar esta lesión central de células gigantes multinucleadas en mandíbula para ampliar los conocimientos clínicos, radiográficos e histopatológicos para colaborar con nuestros estudiantes y colegas odontólogos en el buen direccionamiento diagnóstico de lesiones intraóseas de carácter no odontogénico.

\section{Reporte de caso}

Paciente de sexo femenino de 18 años de edad, sin antecedentes médicos de importancia, que acude a la consulta de la clínica de especialidades odontológicas de la Universidad Católica de Cuenca Sede Azogues por presentar odontalgia de la pieza 3.6. Al examen clínico presentó asimetría facial con predominancia de tamaño derecho, sin ganglios palpables. (Fig. 1). Al examen clínico intraoral presentó restauraciones dentales, mala posición dental bimaxilar y en zona del 36 un leve abultamiento asintomático, y de consistencia firme a la palpación sin cambio de coloración de la mucosa. (Fig. 2)

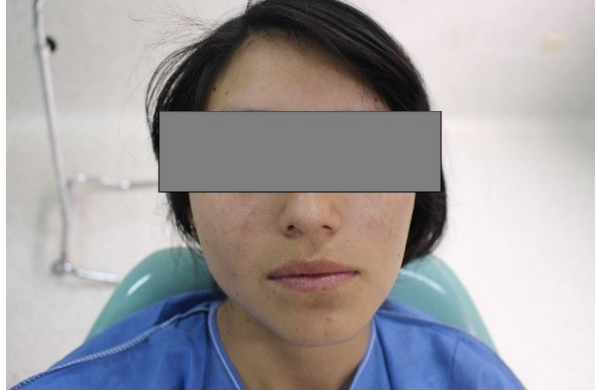

Fig. 1. Paciente femenina de 18 años, asintomática con ligera asimetría facial

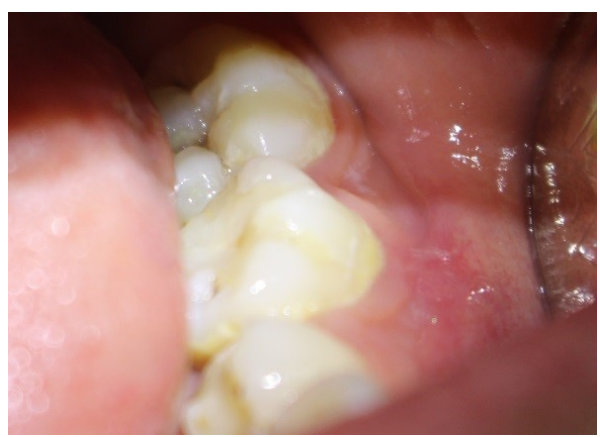

Fig. 2. Se observa ligera tumefacción y cambio de coloración gingival a nivel apical de diente 3.6

Dentro de los exámenes complementarios se realizaron exámenes radiográficos, en los que se observó una lesión radiolúcida unilocular con bordes escleróticos y rizólisis asociada a la raíces de la pieza dental 3.6 (Fig. 3 y 4); además, se observó zona radiopaca compatible con restauración dental con filtración que sugiere caries recidivante, manejando un diagnóstico presuntivo de quiste periapical. Además, en el hemograma completo presento un aumento de monocitos.

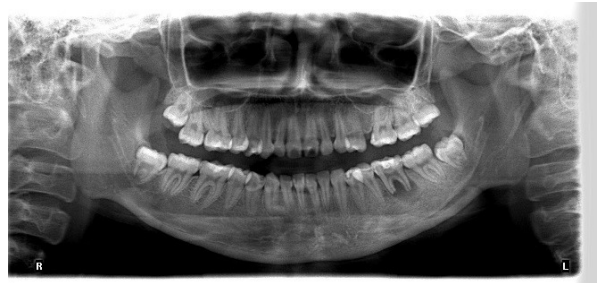

Fig. 3. Radiografía Panorámica sin alteraciones radiográficas en estructuras faciales perimandibulares

Se realizó enucleación de lesión fibrosa de $15 \mathrm{~mm}$ de diámetro color café pardo y curetaje óseo acompañado de exodoncia quirúrgica del primer molar inferior izquierdo (Fig. 5). Posterior a la exéresis y fijación de la lesión, se realizó un examen histopatológico en el que observamos: tejido fibrocolágeno, abundantes vasos sanguíneos y tejido 


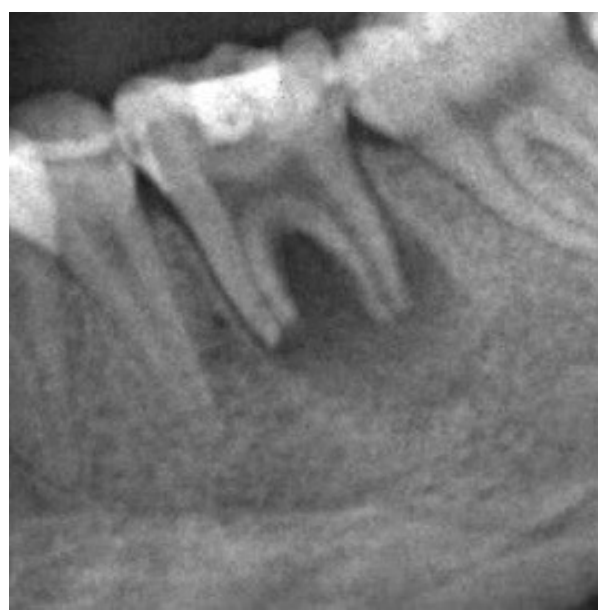

Fig. 4. lesión radiolúcida unilocular con bordes escleróticos y rizólisis asociada a la raíces de la pieza dental 3.6

adiposo formando el estroma donde se observó la presencia moderada de polimorfonucleares neutrófilos. Además se distinguieron células gigantes multinucleadas (osteoclasto like) dispersas en el estroma. Los bordes de la lesión se presentaron regulares y bien diferenciados (Fig. 6), determinando el diagnóstico definitivo de Lesión Central de Células Gigantes Multinucleadas.

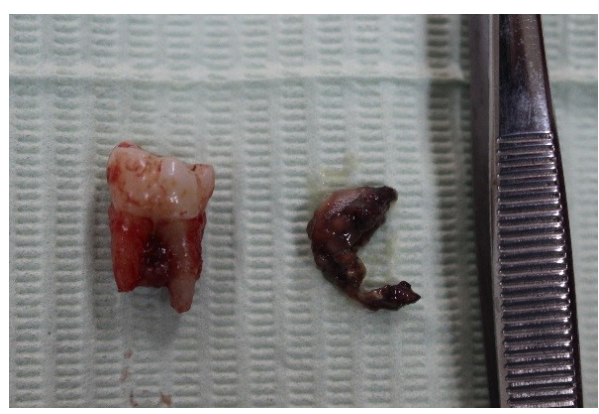

Fig. 5. Enucleación de lesión fibrosa de $15 \mathrm{~mm}$ de diámetro color café pardo y exodoncia quirúrgica del primer molar inferior izquierdo

Luego del diagnóstico histopatológico se envió un examen de hormona paratiroidea el cual mostró valores dentro de los rangos de normalidad, para descartar la presencia de un tumor pardo del hiperparatiroidismo el cual se presenta clínica e histológicamente igual a la LCCGM.

Se realizaron controles periódicos donde al sexto mes se puede observar radiográficamente la presencia de radiopacidad difusa dentro del defecto óseo sugerente de neo formación ósea, sin evidencia radiográfica de recidiva (Fig. 7).

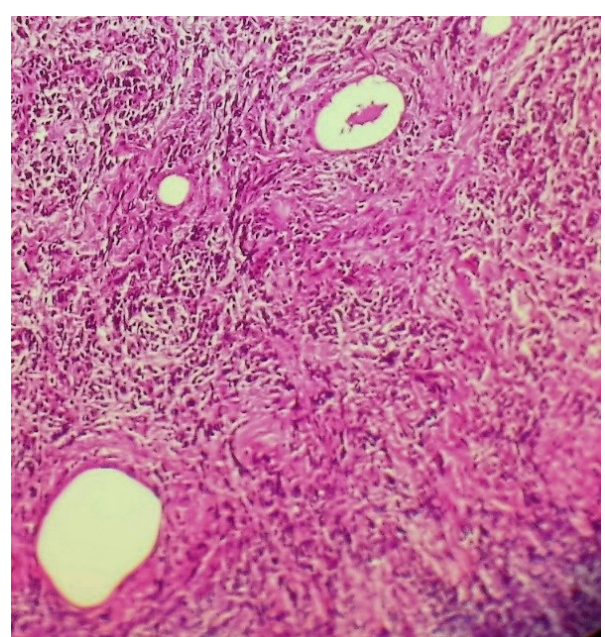

Fig. 6. (10X) tejido fibrocolágeno, abundantes vasos sanguíneos y tejido adiposo formando el estroma además se observa presencia moderada de polimorfonucleares neutrófilos; y células gigantes multinucleadas (osteoclasto like) dispersas en el estroma
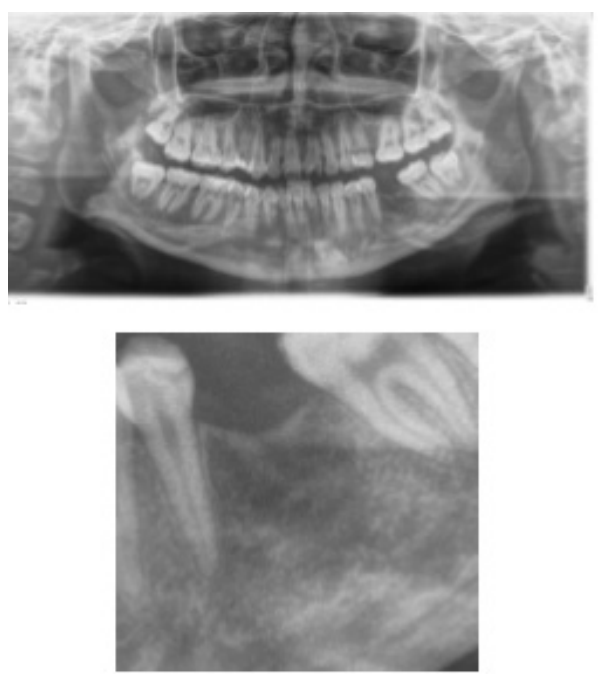

Fig. 7. Radiopacidad difusa sugerente de neo formación ósea

\section{Discusión}

Duque y col. $2012^{7}$ afirman que la lesión central de células gigantes (llamada también granuloma central de células gigantes) es una lesión intraósea de tipo benigna, cuya etiología está asociada a varios factores de principal prevalencia en procesos traumáticos por la cual se origina una reparación local debido posiblemente a una hemorragia producto del mismo. Por estas razones la $\mathrm{OMS}^{2}$ lo define como una lesión osteolítica localizada benigna, algunas veces agresiva, con tejido fibroso y áreas sangrantes con depósitos de hemosiderina y células parecidas a osteoclastos. Por otro lado, Barnes y col. en $2005^{2}$ afirman que se trata de una anomalía del desarrollo, que puede, o no, estar asociada a síndromes genéticos como 
la neurofibromatosis, el querubismo, síndrome de Noonan, de Ramón. En otros estudios, como de Portelles y col. en 2011 afirman que es producto de una respuesta exagerada a un traumatismo inespecífico que se impulsa a través del ligamento periodontal y de los remanentes del folículo para la resolución de la hemorragia. Estudios de Gorling y col. ${ }^{8}$ determinaron que la lesión tiene mayor afección en huesos maxilares con preferencia en la mandíbula, teniendo mayor incidencia de casos en la región de premolares y molares con mayor frecuencia en mujeres debido a la producción hormonal de estrógenos durante el embarazo, así como también observando el mayor número de casos durante la segunda y tercera década de vida. Duque y col. en $2012^{7}$ plantean que la alteración de los maxilares expande las corticales óseas con o sin asimetría facial notoria, las cuales pueden tener un tamaño variado de crecimiento lento, con una mucosa de revestimiento la cual puede observarse eritematosa y sensible a la palpación pudiendo afectar a los gérmenes dentales y la dentición permanente. Por su parte Gorling y col. ${ }^{8}$ determinaron que la lesión está compuesta por fibroblastos en forma de huso dispuestas en un tejido vascularizado con depósitos de hemosiderina con células gigantes multinucleadas semejantes a osteoclastos dispersas en forma uniforme o en aglomerados, encontrándose mitosis característico de la LCCG. Jadu y col. en 2013 afirman que la lesión presenta características radiográficas variables que suelen ser confundidas con otras lesiones, presentándose como un defecto radiolúcido unilocular o multilocular con bordes desde bien definidos hasta mal definidos con expansión de la cortical que según autores puede presentar rizoclasia y desplazamiento dental. Nuestro caso se asemeja mucho a las características descritas por los autores en cuanto a presentación clínica, radiográfica e histopatológica. Además, en nuestro caso no se la asocia a algún síndrome ni anomalía hormonal. Es por tanto a criterio de los autores, sin tener un antecedente claro de la etiología de la lesión suponer que se trata de una lesión central de células gigantes multinucleadas secundario a un traumatismo.

\section{Conclusión}

La lesión central de células gigantes se ubica dentro del amplio ámbito de patologías orales de origen no dental, que se observan en la mayor parte de casos como hallazgos radiográficos. Es por tanto responsabilidad del odontólogo manejar varios diagnósticos diferenciales de imágenes radiolúcidas en radiografías periapicales y panorámicas, además de realizar biopsias y exámenes histológicos de lesiones intraóseas para evitar un mal direccionamiento diagnóstico que conlleva inevitablemente a una mala terapéutica y consecuentemente una mala praxis odontológica.

\section{Referencias}

1 Potelles A, Heredia J, Granuloma central de células gigantes. Rev Cubana Estomatol. 2011; 48 (1): 8488.
2 Barnes L, Evenson J, Reichart P. Who Classification of Tumours. Pathology and Genetics of Head and Neck Tumours. Lyon: IARC Press; 200.

3 Jadu F, Pharoah M, Lee L, Baker C. Central giant cell granuloma of the mandibule condyle: a case report and review of the literature Dentomaxillofac Radoil. 2011; 40: 60-64.

4 Santa Garay J. Lesiones seudo tumorales de la mucosa de la boca. Atlas de Patología de complejo bucal. Editorial Científico Técnica; 2013 p. 152- 3.

5 Bezerra R, Flores P, Neves F. Surgical treatment of aggressive central giant cell granuloma on the jaw using the Weber Ferguson approach: a case report. 2014 Universidade Federal do Brasil 2014.

6 Ayelén M, Portelles M, Heredia C. Gigant cell central granuloma. Revista Cubana de Estomatología. 2011:48(1)84-88.

7 Duque F, Franco L, Ardila C. Central giant cell granuloma: Presentation of ten cases. 2012. Facultad de Odontología Universidad de Antioquia. Colombia.

8 Gorling R, Goldman H. Patología Oral. 2013. Salvat Editores.

9 Lange J, Van de Akker H, Van del Borg. Central giant cell granuloma of the jaw: a review of the literature with emplais on therapy options. 2007.

10 Harris M. Central giant cell granuloma with calcitonin therapy. Oral Maxillofac. 2011. 